\title{
Experiences with amine fluoride containing products in the management of dental hard tissue lesions focusing on Hungarian studies: A review
}

\author{
Melinda Madléna \\ Department of Paedodontics and \\ Orthodontics, Semmelweis University \\ Budapest, Hungary \\ Corresponding author: \\ Melinda Madléna \\ Szentkirályi 47 \\ 1088 Budapest \\ Hungary \\ madlena.melinda@dent.semmelweis-univ.hu \\ Tel.: + 36309855300 \\ Fax.: + 3612668269
}

Received: 9 April 2013

Accepted: 26 April 2013

Copyright (C) 2013 by

Academy of Sciences and Arts

of Bosnia and Herzegovina.

E-mail for permission to publish:

amabih@anubih.ba

\section{Introduction}

In spite of the caries decline experienced in the industrialised countries in twelve year olds, in Hungary caries has remained a major problem in older age groups, concerning the dental hard tissues (1). This situation is strongly associated with bad oral hygiene,
Fluorides play a significant role in the promotion of oral health, fostering remineralization, inhibiting demineralization processes in the enamel, and having antibacterial activity. The effects of fluorides are mostly exerted by their topical effect. The beneficial effect of amine fluorides $(\mathrm{AmF})$ on caries and dental plaque reduction has been known for a long time. The caries reducing and plaque-inhibiting effect of stannous fluoride $\left(\mathrm{SnF}_{2}\right)$ was also reported. However, the combination of amine fluoride/stannous fluoride has shown a much better inhibition of plaque accumulation then these products alone. There have been several clinical studies with $\mathrm{AmF}$ or $\mathrm{AmF} / \mathrm{SnF}_{2}$ products, using toothpaste, gel, combination of toothpaste and gel/fluid, toothpaste and mouth rinse. The aim of this article is to review the clinical experiences with these products based on Hungarian studies. The first Hungarian studies with AmF containing gel were published by Szöke and Kozma (1989) and Dénes and Gábris (1991). Madléna et al. (2002) performed a study with an AmF-containing toothpaste and gel in high risk groups of adolescents. The first Hungarian study with $\mathrm{AmF} / \mathrm{SnF}_{2}$ products was published by Bánóczy et al. (1989). Based on the favourable results of these products used in combination for 12 weeks, other studies (Madléna et al. 2004, 2012) assessed the effects of toothpastes and mouth rinse containing $\mathrm{AmF} / \mathrm{SnF}_{2}$ on plaque accumulation, within a shorter period of time, in young adults and orthodontic patients. Conclusion. Regular use of different oral hygienic products containing an $\mathrm{AmF}$ and $\mathrm{AmF} / \mathrm{SnF}_{2}$ combination contributes to the prevention of plaque accumulation and consequently to the prevention of dental diseases.

Key words: Amine fluoride, Amine fluoride/Stannous fluoride, Plaque accumulation, Prevention, Oral health.

that is improper oral hygiene habits of individuals (2).

Orthodontic treatment mainly with fixed appliances represents a special situation because of the increased retention of plaque, which can cause an increased risk of caries and periodontal diseases (3). For the pre- 
vention of carious lesions it is anyhow necessary to perform proper mechanical plaque removal. However, most people have no adequate mechanical cleaning method for various reasons, so it is necessary to improve the removal of plaque with chemical agents (4). The combination of mechanical and chemical methods ensures greater effect as after the mechanical reduction of the amount of plaque only a disorganized thin layer will remain on the tooth surface, which may be further reduced easily with chemical agents (5).

Fluorides play a significant role in the promotion of oral health, fostering remineralization, inhibiting the demineralization processes in the enamel, and having antibacterial activity. These beneficial effects may be improved when fluoride is associated with amin -or stannous ions (6).

\section{Amine fluorides in dentistry}

Amine fluoride $(\mathrm{AmF})$ is an organic type of fluoride associated with a reduction in dental plaque adhesiveness, due to the greater affinity of hydrophilic counter-ions to the enamel surface. It spreads over all surfaces in the oral cavity especially quickly (due its tenside character), shows longer clearance in the oral cavity and dental plaque, and has a pronounced activity on plaque. AmF is strongly glycolytic (for 3-6 hours) and develops a highly bacteriostatic and bactericide effect (5).

The use of amine fluorides in dentistry was first recommended by Mühlemann and co-workers in 1960 (7). Based on their favourable characteristics in in vitro and in vivo studies, amine fluoride products were suggested as alternatives or adjuncts for systemic fluoridation by Mühlemann in 1967, and Schmid in $1983(8,9)$. However according to the opinion of Ahrens from 1983, the results of these studies were influenced by different factors, where age, methods and frequency of application, fluoride-concentration and duration played a role and made comparability difficult (10).

As a result the favourable effects AmFs could be successfully applied in reducing the prevalence of dental diseases. For the general public, $\mathrm{AmF}$ is available in the form of dentifrices, gels, mouth rinses, and for healthcare professionals in the form of prophylaxis pastes.

\section{Clinical studies with amine fluoride containing (Elmex ${ }^{\circledR}$ ) products}

Clinical studies with amine fluorides have been performed using toothpaste, gel, with combined use of toothpaste and gel/fluid, or with combined use of toothpaste and mouth rinse.

In the early period there were more clinical studies published on AmF toothpaste, where the first was published in 1968 by Marthaler (11). Most of them showed considerable reduction in caries prevalence [in DMFT (Decayed, Missing, Filled Teeth)/ DMFS (Decayed, Missing, Filled Surfaces) values between 7.1 and 35\%] similar to those

Table 1 Clinical studies with amine fluoride toothpastes

\begin{tabular}{lllllll}
\hline Authors & Year & Duration (year) & Probands $(\mathrm{n})$ & Age (year) & Caries reduction \% DMFT-S & $\mathrm{p}$ \\
\hline Marthaler & 1968 & 7 & $142 / 118$ & $6-8$ & $23-35$ & $<0.001$ \\
Patz and Naujoks & 1970 & 3 & $?$ & $15-18$ & 7.1 & $\mathrm{n}$ \\
Marthaler & 1974 & 6 & $50 / 59$ & 7.5 & 33 & $<0.02$ \\
Cahen et al. & 1982 & 3 & $668 / 708$ & $6-8$ & $21.6 ; 20.9$ & $<0.001$ \\
Leous & 1995 & 3 & $330 / 140$ & $18-20$ & 25.6 & $\mathrm{~ns}$ \\
\hline
\end{tabular}


Tabela 2 Clinical studies with amine fluoride gels

\begin{tabular}{lllllll}
\hline Authors & Year & Duration (ys) & Probands (n) & Age (vs) & Caries reduction\% (DMFS) & $\mathrm{p}$ \\
\hline Marthaler & 1970 & 3 & $?$ & $6-7$ & 45 & $\mathrm{p}<0.05$ \\
Shern et al. & 1970 & 2 & $?$ & $?$ & 31 & $\mathrm{p}<0.05$ \\
Franke & 1977 & 7 & $?$ & 7 & 45 & $\mathrm{p}<0.05$ \\
Obersztyn, Kolwinski & 1983 & 1.5 & $787 / 449$ & $19-20$ & 41 & Not calc. \\
Szőke and Kozma & 1989 & 3 & $134 / 122$ & $6-7$ & 53 & $\mathrm{p}<0.001$ \\
\hline
\end{tabular}

studies performed showing amine fluoride gel caries reductions of $31-53 \%$, or with combined use of AmF containing products (Tables 1,2). Most of these studies evaluated caries prevalence, but some of them assessed oral hygiene, and also reported a significant improvement in the test groups.

\section{Longitudinal studies}

The first Hungarian study with AmF gel was performed by Szőke and Kozma in 1989 (12). In this study, the AmF gel was applied for 3 years in children who were 6 years old. Besides the significant improvement in oral hygiene in the test group compared to the controls, there was a significant difference in the caries increment between the two groups, in both DMFT and DMFS values.

\section{Studies in high risk groups}

A study performed in orthodontic patients was published by Dénes and Gábris in 1991 (13). This double blind, randomised study was performed in adolescents treated with fixed orthodontic appliances. During the examination period, the authors compared the effect of Elmex gel and fluid application on caries increment compared to the control group, without intensive fluoridation. Regarding their main results, the Elmex ${ }^{\circledR}$ products reduced the caries increment in orthodontic patients after an average 18 months (average treatment time), the reduction was much higher in both Elmex ${ }^{\circledR}$ groups than in the controls. The reduction in caries increment was the best and highest in the group using gel, with a reduction of $79 \%$.

Another longitudinal study was performed showing the beneficial effect of toothpaste and gel containing AmF in high risk groups of adolescents (14). The study consisted of two parts. During the baseline examinations the risk of oral diseases (assessing caries prevalence, oral hygiene, salivary characteristics, and socio-economic factors) was determined in groups of adolescents living in different localities of Hungary: in Budapest (the capital of Hungary, and in Debrecen, which is the second largest city in the country in the eastern part of Hungary). Then, on the basis of the baseline findings where high risk was shown in the examined population, during the follow up study, a school based preventive program was established scheduled for two years, with the different use of products containing amine fluoride (toothpaste and gel) in these high risk groups. The participants were stratified according to their schoolclasses, and divided into two test and one control groups in both cities. Test group "A" used tootpaste and gel containing AmF, Test group „B” used toothpaste and placebo gel containing AmF, and the control („C”) group continued their usual oral care habits without AmF containing products.

The DMFT, DMFS and Visible Plaque Index (VPI) values (according to Ainamo and Bay, 1983) (15) were evaluated at baseline and after two years. The DMFT increment was 
significantly lower in both test groups compared to the control group. Concerning the DMFS values, the caries increment was significantly lower in the group with combined use of toothpaste and gel containing $\mathrm{AmF}$ than in the control group (Figures 1 and 2).

The combined use of amine fluoride containing toothpaste and gel provided a significant reduction in DMFS mean values (38\% including white spot lesions) and visible plaque index values $(18 \%)(\mathrm{p}<0.05)$. The VPI values decreased in all three groups due to regular oral health instruction and motivation, but there was only a significant reduction in the groups where the participants used toothpaste and gel containing AmF together.
In the above-mentioned population the therapeutic value of products containing AmF was assessed statistically, by logistic regression analysis (16). The results showed that the chance of remineralization of buccal incipient lesions was higher in the group using gel and toothpaste together than in the other test group (using only toothpaste) and much higher than in the control group.

Summarizing the results: combined use of products containing amine fluoride (toothpaste and gel) provided more pronounced caries reduction, improvement of oral hygiene and remineralisation effect than use of the toothpaste alone, in adolescents with high risk and without a systemic fluoride background.

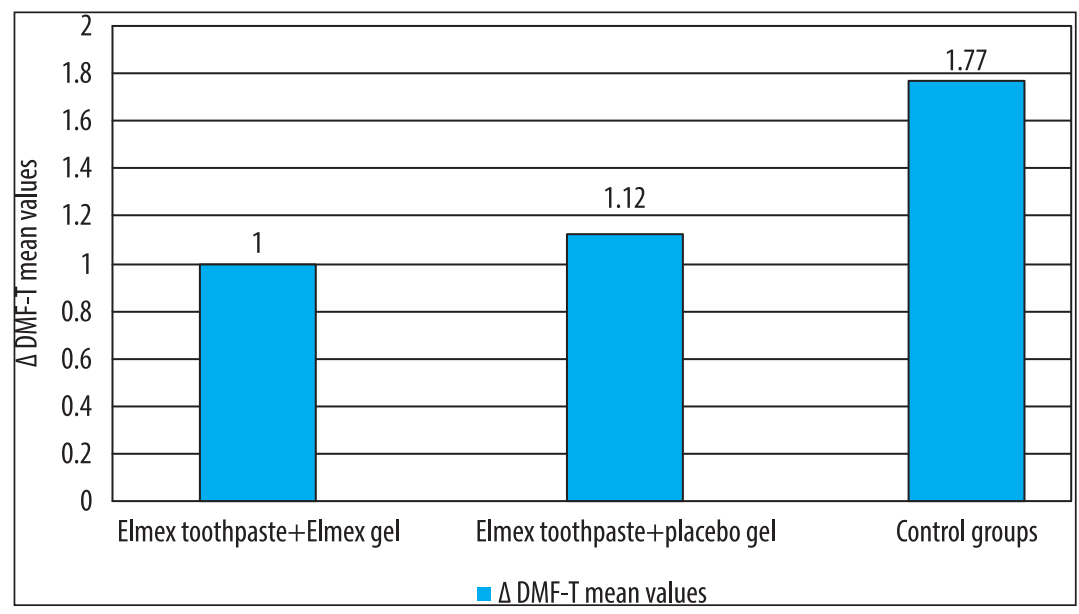

Figure 1 Two-year incremental DMF-T findings for subjects who completed the study $(14)(p<0.05)$.

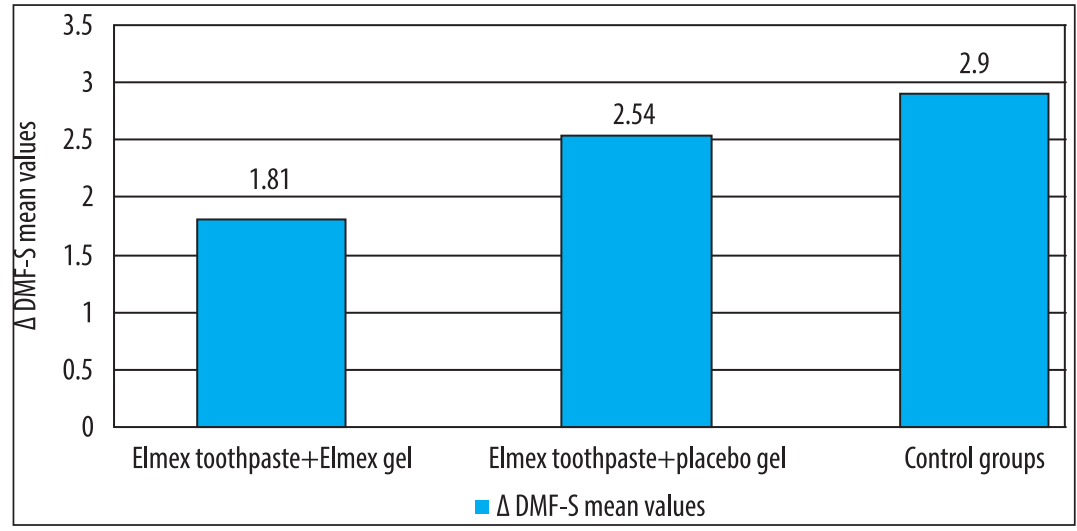

Figure 2 Two-year incremental DMF-S summary for subjects who completed the study (14) $(p<0.05)$. 


\section{Amine fluorides/stannous fluorides in dentistry}

The beneficial effect of amine fluorides on caries and dental plaque reduction has been known for a long time. The caries reducing and plaque inhibiting effect of stannous fluoride $\left(\mathrm{SnF}_{2}\right)$ was also reported many years ago. Stannous fluoride releases both $\mathrm{F}^{-}$and $\mathrm{Sn}^{2+}$ ions in the oral cavity, which ensure effectiveness against caries and an antimicrobial characteristic (17). However, the combination of amine fluoride /stannous fluoride $\left(\mathrm{AmF} / \mathrm{SnF}_{2}\right)$ showed much better inhibition of plaque accumulation then these products alone $(18,19)$. AmF possesses antibacterial activity, which could be enhanced when amine fluoride is associated with stannous fluoride (6). Oral hygienic products containing amine fluoride/stannous fluoride reduce acid production within the dental plaque (20) and retard supragingival plaque regrowth (21-23), therefore these products could be more effective in the oral cavity. The antibacterial effect of $\mathrm{AmF} / \mathrm{SnF}_{2}$ seems to be more prolonged in patients who are not at high risk, with a smaller amount of plaque (24).

The first summarized results of clinical trials investigated the plaque and gingivitis inhibiting effects of the $\mathrm{AmF} / \mathrm{SnF}_{2}$ combination and were published in 1991 (25). After the mouth rinse a toothpaste containing $\mathrm{AmF} /$ $\mathrm{SnF}_{2}$ also became available and these products could be found on the market as Meridol ${ }^{\circledR}$ mouth rinse and $\mathrm{Meridol}^{\circledR}$ toothpaste.

\section{Clinical studies with products containing amine fluoride/stannous fluoride $\left(\right.$ Meridol $^{\circledR}$ )}

Clinical studies with amine fluoride/stannous fluoride were performed using toothpaste, mouth rinse or with combined use of toothpaste and mouth rinse. Relatively few studies have reported the clinical results of the use of $\mathrm{AmF} / \mathrm{SnF}{ }_{2}$ toothpaste and com- bined use of toothpaste and mouth rinse. Although these studies did not evaluate the caries reducing effect directly, the plaque reduction could be associated with all plaque induced dental diseases (caries and periodontal diseases). The examinations proved the effectiveness of this combination over various periods of time.

\section{Medium term studies}

The first study, lasting for 12 weeks, was published by Bánóczy and co-workers in 1989 (26), performed on 92 schoolchildren with a mean age of 12.4 years, showing that use of $\mathrm{AmF} / \mathrm{SnF}_{2}$ toothpaste resulted in significant reduction of plaque accumulation and gingival inflammation, but the combined use of toothpaste and mouth rinse proved to be more effective than the use of toothpaste alone. In this study participants were involved who were randomly distributed in four groups:

- Group 1.: used placebo toothpaste

- Group 2.: used amine fluoride/stannous fluoride toothpaste (Meridol ${ }^{\circledR}$ )

- Group 3.: used placebo toothpaste and amine fluoride/stannous fluoride rinse $\left(\right.$ Meridol $^{\circledR}$ )

- Group 4.: used Meridol ${ }^{\circledR}$ toothpaste and Meridol $^{\circledR}$ rinse

The examined parameters were: Plaque Index (PI, according to Silness and Löe, 1964) (27) and Sulcus Bleeding Index (SBI, according to Mühleman and Son, 1971) (28). Concerning the results of the Plaque Index values, the greatest decrease was seen in the fourth group (using $\mathrm{AmF} / \mathrm{SnF}_{2}$ containing toothpaste and mouth rinse together) which was statistically significantly higher than in the other groups. Similar results were found with the Sulcus Bleeding Index values (Figure 3). A significant increase in enamel fluoride content was observed after use of the test toothpaste alone or after a combined use of these products. The plaque fluoride con- 


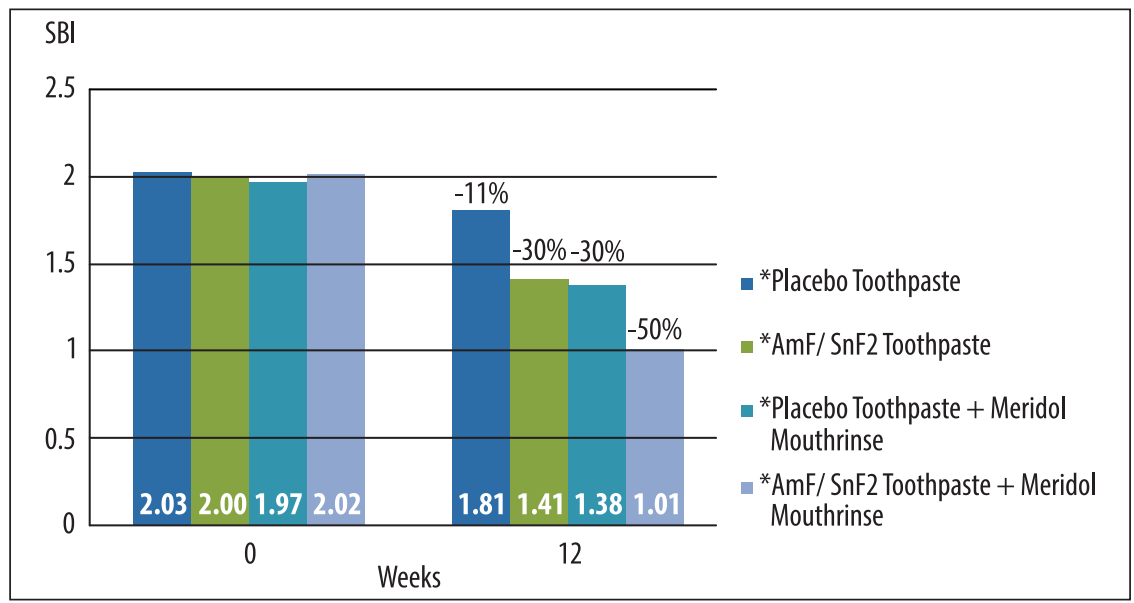

Figure 3 Decrease in the Sulcus Bleeding Index values after 12 weeks' use $(p<0.05)$.

tent also showed a statistically significant increase in the fourth group.

Later, a five month, double blind study was performed to evaluate the effectiveness of toothpaste and mouth rinse containing $\mathrm{AmF} / \mathrm{SnF}_{2}$ on the accumulation of dental plaque and gingivitis, and the remineralizing effects of these products, in cases of exposed root surfaces and root surface caries, compared with the sodium fluoride $(\mathrm{NaF})$ system (29). Forty-four adults were randomly divided into two groups: group 1 used toothpaste and mouth rinse containing $\mathrm{AmF} / \mathrm{SnF}_{2}$, group 2 used $\mathrm{NaF}$ toothpaste and mouth rinse twice a day. The participants brushed their teeth with standardized "Multi-effect" toothbrushes, mouth rinses were used after each tooth brushing, keeping $10 \mathrm{ml}$ of the solution in the mouth for one minute. By the end of the examinations a significantly higher reduction of Plaque Index (according to Silness and Löe, 1964) (27) and Sulcus Bleeding Index (according to Mühlemann and Son, 1971) (28) was found in both groups. The Root Caries Index (RCI) decreased in both groups, and the reduction in mean RCI values was more pronounced and significantly higher using $\mathrm{AmF} / \mathrm{SnF}_{2}$ products $(47.4 \%)$ than in the NaF group (10.0\%).

On the basis of these two studies, it may be concluded that in both studies clinically and statistically significant improvements were found in relation to plaque and gingiva indices. The improvement by $63.7 \%$ in the Plaque Index in the longer study was much better than in the shorter one (33.3\%), which showed the contribution of time of application. The results of the first study showed the beneficial effects of $\mathrm{AmF} / \mathrm{SnF}_{2}$ products on $\mathrm{F}$ content of plaque and enamel, which can help to prevent carious processes Further, the results of the second study show the efficacy of products containing $\mathrm{AmF} / \mathrm{SnF}_{2}$ in adults with periodontal disease (exposed root surfaces) and regarding the changes of RCI mean values the superiority was shown of $\mathrm{AmF} / \mathrm{SnF}_{2}$ combination over combinations containing $\mathrm{NaF}$.

\section{Short term studies}

Based on the previously experienced favourable results of combined use of products containing $\mathrm{AmF} / \mathrm{SnF}_{2}$ after 12 weeks use (26), another Hungarian study aimed to assess the effects of different use of toothpaste and mouth rinse containing $\mathrm{AmF} / \mathrm{SnF}_{2}$ within a shorter period of time (4 weeks) in young adults $(30,31,32)$.

The study population consisted of 42 healthy probands, with a mean age of around 28 years. The criteria of the involvement in 


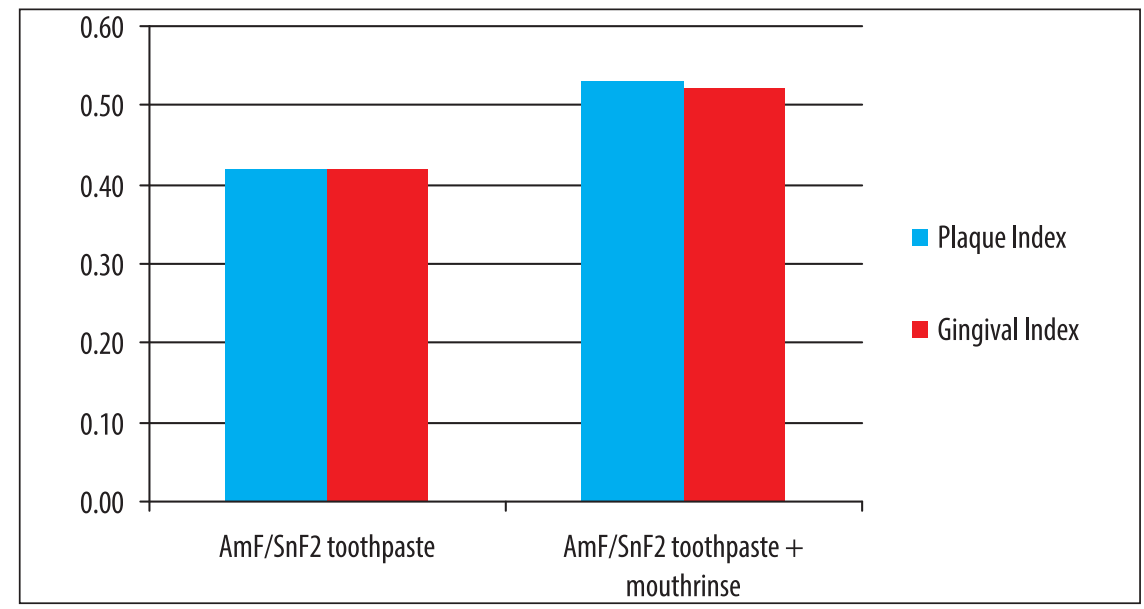

Figure 4 Reduction in Plaque Index and Gingival Index after four weeks' use $(30)(p<0.01)$.

this study were: having no antibiotic or systemic therapy, taking no drugs that influence oral flora and gingival health, being without clinical signs of periodontitis [PPD (Periodontal Pocket Depth) $<4 \mathrm{~mm}$ ] and having at least 20 natural teeth. The participants were randomly divided into two groups:

Group 1: used toothpaste containing $\mathrm{AmF} / \mathrm{SnF}_{2}$ twice a day (morning and evening) for tooth brushing with a Meridol $^{\circledR}$ toothbrush for 3 minutes and Group 2: used toothpaste containing $\mathrm{AmF} / \mathrm{SnF}_{2}$ for tooth brushing for 3 minutes with a Meridol $^{\circledR}$ toothbrush and after tooth brushing rinsed with a mouth rinse containing $\mathrm{AmF} / \mathrm{SnF}_{2}$.

The probands exercised no oral hygiene for two days prior to baseline examination. On the days of baseline and final examinations they had no breakfast and exercised no oral hygiene. Plaque accumulation was assessed by their full mouth score on the Plaque Index according to Silness Löe (1964) (27). Gingival status was scored for the whole mouth, following the criteria of the Gingival Index according to Löe and Silness (1963) (33). After four weeks the patients were re-examined without previous oral hygiene and breakfast by the same examiner, and the results were recorded blindly.

Concerning the results in this short term (four weeks) clinical study on young adults, both the regular use of an $\mathrm{AmF} / \mathrm{SnF}_{2}$ toothpaste alone, as well as the combined use of the toothpaste and mouth rinse resulted in a significant reduction in dental plaque (and consequently the development of caries lesions as well) and Gingival Index (PI and GI) values. The reduction of PI and GI values was significantly greater in the combined $\mathrm{AmF} / \mathrm{SnF}_{2}$ group than in the group using toothpaste only (Figure 4).

It was mentioned earlier that orthodontic patients belong to high risk groups because of increased plaque retention and difficulties in performing proper oral hygiene. Few investigations appear to have been undertaken into the effects of $\mathrm{AmF}$ or $\mathrm{SnF}_{2}(13,34$, 35). Øgaard et al. (36) examined the effect of combined use of $\mathrm{AmF} / \mathrm{SnF}_{2}$ toothpaste/ mouth rinse compared with $\mathrm{NaF}$, in relation to the maxillary anterior teeth, during orthodontic treatment with fixed appliance. They found better oral health in the tested groups using $\mathrm{AmF} / \mathrm{SnF}{ }_{2}$ products daily (36).

Based on the beneficial effects of AmF/ $\mathrm{SnF}_{2}$ products in young adults, a similar study was repeated in high risk groups, namely orthodontic patients treated with a fixed appliance, where the aim was to investigate the influence of toothpaste and mouth rinse containing $\mathrm{AmF} / \mathrm{SnF}_{2}$ on plaque accumulation and gingival health, in a similar short 
term study (37). The examined persons were 40 (by the end of the study 39) young orthodontic patients with a mean age of around 20 years. The probands were divided into similar two groups, as in the previous study: Group 1: used toothpaste containing AmF/ $\mathrm{SnF}_{2}$ twice a day (morning and evening) for tooth brushing with a Meridol ${ }^{\circledR}$ toothbrush for 3 minutes; Group 2: used toothpaste containing $\mathrm{AmF} / \mathrm{SnF}_{2}$ for tooth brushing for 3 minutes with a Meridol ${ }^{\circledR}$ toothbrush and after tooth brushing rinsed with mouth rinse containing $\mathrm{AmF} / \mathrm{SnF}_{2}$. Besides the PI and GI, the parameters examined were extended to include Bleeding on Probing (BoP) and Periodontal Probing Depth (PPD).

Regarding the results, the use of products containing $\mathrm{AmF} / \mathrm{SnF}_{2}$ resulted in beneficial clinical effects on plaque accumulation (so consequently on the choice of the development of carious lesions) and gingival health, after placement of fixed orthodontic appliances. PI (as well as GI) decreased significantly in both examination groups. The reduction of PI (and GI) values was greater in the combined $\mathrm{AMF} / \mathrm{SnF}_{2}$ group than in the group using toothpaste only, but there were no statistically significant differences between the two groups in this high risk population during the short period of time. The experiences were similar in the values of BoP and PPD (significant differences could be found in the control and test groups, but were not noticed between the two groups). These beneficial effects may be pronounced after long term and combined use of $\mathrm{AmF} /$ $\mathrm{SnF}_{2}$ products in this high risk population treated with fixed appliances.

\section{Conclusion}

Most of the Hungarian studies performed related to children and adolescents, and mainly high risk groups. The results, statistically evaluated, seem to be best in the groups with combined use of oral hygiene products containing different amine fluoride or amine fluoride/stannous fluoride (toothpaste and gel or toothpaste and mouth rinse).

Conflict of interest: The author declares that she has no conflict of interest.

\section{References}

1. Madléna M, Hermann P, Jáhn M, Fejérdy P. Caries prevalence and tooth loss in Hungarian adult population: results of a national survey. BMC Public Health. 2008;8:364.

2. Madléna $M$, Hermann $P$, Tollas $O$, Gerle J, Fejérdy P. Oral hygienic, nutritional habits and dental surgeon attendance of Hungarian adult population [In Hungarian]. Fogorv Sz. 2007;100(3):91-7.

3. Madléna M. The importance and possibilities of proper oral hygiene in orthodontic patients. In: Bourzgui F, editor. Orthodontic: basical aspects and clinical consideration. Rijeka: INTECH; 2012. p. 69-110.

4. Binney A, Addy M, Newcombe RG. The plaque removal effects of single rinsings and brushings. J Periodontol. 1993;64(3):181-5.

5. Brecx M. Strategies and agents in supragingival chemical plaque control. Periodontol 2000. 1997;15(1):100-8.

6. Van Loveren C. Antimicrobial activity of fluoride and its in vivo importance: identification of research questions. Caries Res. 2001;35(suppl 1):65-70.

7. Mühlemann HR, König KG, Marthaler TM, Schait A, Schmid H. Organic Fluoride [In German].Schweiz Mschr Zahnheilk. 1960;70(12):1037-47.

8. Mühlemann HR. The caries-preventing effect of the amine fluorides. 4.10 years of experiences [In German]. Quintessenz. 1967;18(8):109-17.

9. Schmid H. Chemistry and surface effects of amine fluoride[In German]. Dtsch Zahnarztl Z. 1983;38 Suppl 1:S9-13.

10. Ahrens G. Efficiency of fluoride dosage forms: solutions and gels[In German]. Dtsch Zahnarztl Z. 1983;38 Suppl 1:S65-9.

11. Marthaler TM. Caries inhibition after seven years of supervised use of an amine fluoride dentifrice. Br Dent J. 1968;124(4):510-5.

12. Szöke J, Kozma M. Results of 3-year study of toothbrushing with a fluoride amine gel [In German]. Oralprophylaxe. 1989;11(4):137-43.

13. Dénes J, Gábris K. Results of a 3-year oral hygiene programme including amine fluoride products treated with fixed orthodontic appliances. Eur J Orthodont. 1991;13(2):129-33. 
14. Madléna M, Nagy G, Gábris K, Márton S, Keszthelyi G, Bánóczy J. Effect of Amine Fluoride Toothpaste and Gel in High Risk Groups of Hungarian Adolescents: Results of a Longitudinal Study. Caries Res. 2002;36(2):142-6.

15. Ainamo J, Bay I. Problems and proposals for recording gingivitis. Int Dent J. 1975; 25(4) 229-35.

16. Márton S, Nagy G, Gábris K, Bánóczy J, Madléna M. Logistic regression analysis of oral health data in assessing the therapeutic value of amine fluoride containing products. Oral Health Dent Manag. 2008;7(4):26-9.

17. Lilienthal B. The effect of a stannous fluoride mouthwash on acid formation in the mouth and some observations on the mechanism of inhibition. Aus Dent J. 1956;1(4):221-7.

18. Mühlemann. HR, Saxer UP, Moermann W. Reduction of plaque and gingivitis by stannous fluoride stabilized with amine fluoride. Caries Res. 1981;15(2):186.

19. Renggli HH. Plaquehemmender Effekt kombinierter Fluoridspülungen. Schweiz Monatsschr Zahnheilk. 1983;93(8):581-4.

20. Damen JJ, Buijs MJ, ten Cate JM. Acidogenecity of buccal plaque after a single rinse with amine fluoride-stannous fluoride mouthrinse solutions. Caries Res. 2002;36(1):53-7.

21. Zimmermann A, Flores-de-Jacoby L, Pan P, Pan P. Gingivitis, plaque accumulation and plaque composition under long-term use of Meridol. J Clin Periodontol. 1993;20(5):346-51.

22. Bánóczy J, Gombik A, Szőke J, Nász I. Effect of an antibacterial varnish and amine-fluoride/stannous fluoride (AmF/SnF2) toothpaste on Streptococcus mutans count in saliva and dental plaque of children. J Clin Dent. 1995;6(2):131-4.

23. Arweiler NB, Netuschil L, Reich E. Alcohol-free mouthrinse solutions to reduce supragingival plaque regrowth and vitality. A controlled clinical study. J Clin Periodontol. 2001;28(2):168-74.

24. Weiland B, Netuschil L, Hoffmann T, Lorenz K. Substantivity of amine fluoride/stannous fluoride folloing different modes of application: A randomized, investigator-blind, placebo-controlled trial. Acta Odontol Scand. 2008;66(5):307-13.

25. Flores-Jacoby L. Möglichkeiten der Plaque-und Gingivitis prevention. Berlin: Quintessence-Verlag Gmbh; 1991.

26. Bánóczy J, Szőke J, Kertész P, Tóth Z, Zimmermann P, Gintner Z. Effect of amine fluoride/ stannous fluoride-containing toothpaste and mouthrinsings on dental plaque, gingivitis, plaque and enamel $\mathrm{F}$-accumulation. Caries Res. 1989;23(4):284-8.

27. Silness J, Löe H. Periodontal diseases in pregnancy II.Correlation between oral hygiene and periodontal condition. Acta Odontol Scand. 1964;(2):121-35.

28. Mühlemann HR, Son S. Gingival sulcus bleeding - leading symptomof inital gingivitis. Helv Odont Acta. 1971;15(2):107-13.

29. Bánóczy J, Nemes J. Effect of amine fluoride $(\mathrm{AmF}) /$ stannous fluoride $(\mathrm{SnF} 2)$ toothpaste and mouthwashes on dental plaque accumulation, gingivitis and root-surface caries. Proc Finn Dent Soc. 1991;87(4):555-9.

30. Madléna M, Dombi C, Gintner Z, Bánóczy J. Effect of amine fluoride/stannous fluoride toothpaste and mouthrinse on dental plaque accumulation and gingival health. Oral Dis. 2004;10(5):294-7.

31. Bánóczy J, Dombi C, Gintner Z, Madléna M. Plaque and gingivitis prevention with amine fluoride/stannous fluoride toothpaste and mouthrinse [In German]. Oralprophylaxe. 2005;27(3):95-8.

32. Madléna M, Gintner Z, Bánóczy J, Dombi C. Evaluation of clinical effects ofamine fluoride/stannous fluoride containing toothpaste and mouthrinse [In Hungarian]. Fogorv Sz. 2005;98(6):229-32.

33. Löe H Silness J. Periodontal disease in pregnancy.I. Prevalence and severity. Acta Odontol Scand. 1963;(12):533-51.

34. Boyd RL, Chun YC. Eighteen-month evaluation of the effects of $0.4 \%$ stannous fluorideg el on gingivitis in orthodontic patients. Am J Orthod Dentofac Ortop. 1994;105(1):35-41.

35. Boyd RL, Leggott PJ, Robertson PB. Effects on gingivitis of two different $0.4 \% \mathrm{SnF} 2$ gels. J Dent Res. 1988;67(2):503-7.

36. Øgaard B, Afzelius AA, Larsson E, Adolfsson U. A prospective randomized clinical study on the effects of amine fluoride/stannous fluoride toothpaste/mouthrinse on plaque, gingivitis and initial caries lesion development in orthodontic patients. Eur J Orthod. 2006;28(1):8-12.

37. Madléna M, Bánóczy J, Götz G, Márton S, Kaán M, Nagy G. Effects of Amine and Stannous Fluorides on Plaque Accumulation and Gingival Health in Orthodontic Patients treated with Fixed Appliances: A Pilot Study. Oral Health Dent Manag. 2012;11(2):57-61. 